\title{
ANALYSIS OF REPRODUCTIVE TRAITS AND LAYING EGG RHYTHM OF MAIZE WEEVIL Sitophilus zeamais (Motschulsky)
}

\author{
Nguyen Van Dzuong ${ }^{1,2, *}$, Khuat Dang Long ${ }^{3}$, Le Xuan Que ${ }^{4}$ \\ ${ }^{1}$ Tay Bac University, Son La, Vietnam \\ ${ }^{2}$ Graduate University of Science and Technology, VAST, Vietnam \\ ${ }^{3}$ Institute of Ecology and Biological Resources, VAST, Vietnam \\ ${ }^{4}$ Institute for Tropical Technology, VAST, Vietnam
}

Received 21 March 2019, accepted 10 May 2019

\begin{abstract}
The maize weevil, Sitophilus zeamais (Motschulsky), is a serious pest affecting a wide range of cereal crops, such as maize, rice, beans and other stored dried grains. As a $S$. zeamais female can keep laying eggs for a long time throughout its life after chewing its way into the grains, most development stages of the maize weevil, such as eggs, larvae and pupae, can always be found in stored maize grains. Our experiment with $S$. zeamais on long grain rice showed that 10 days after eclosion and mating, maize weevil females started laying eggs for a period of 150 days. On average, a $S$. zeamais female laid 38.67 eggs, of which, up to $62.81 \%$ were laid in the first $7-8$ weeks (with the remaining $37.19 \%$ in the latter half of the 150 day period), and $55.07 \%$ were laid within day 55-95. The egg laying pattern of $S$. zeamais was modeled using cubic polynomials, which described the maximum percentages of eggs laid at day 15, 35, 75, 95 and 105.
\end{abstract}

Keywords: Sitophilus zeamais, laying egg rhythm, maize weevil, reproduction, store insects.

Citation: Nguyen Van Dzuong, Khuat Dang Long, Le Xuan Que, 2019. Analysis of reproductive traits and laying egg rhythm of maize weevil Sitophilus zeamais (Motschulsky). Tap chi Sinh hoc, 41(2): 29-37. https://doi.org/10.15625/0866-7160/v41n2.13699.

*Corresponding author email: duongdhtb@gmail.com

C2019 Vietnam Academy of Science and Technology (VAST) 


\title{
PHÂN TÍCH ĐẠC ĐIỂM SINH SẢN VÀ NHỊP ĐIỆU ĐẺ TRÚNG CỦA MỌT NGÔ Sitophilus zeamais (Motschulsky)
}

\author{
Nguyễn Văn Dương ${ }^{1,2, *}$, Khuất Đăng Long ${ }^{3}$, Lê Xuân Quế ${ }^{4}$ \\ ${ }^{1}$ Đại học Tây Bắc, Sơn La, Việt Nam \\ ${ }^{2}$ Học viện Khoa học và Công nghệ, Viện Hàn lâm Khoa học và Công nghệ Việt Nam, Việt Nam \\ ${ }^{3}$ Viện Sinh thái và Tài nguyên sinh vật, Viện Hàn lâm Khoa học \\ và Công nghệ Việt Nam, Việt Nam \\ ${ }^{4}$ Viện Kỹ thuật Nhiệt đới, Viện Hàn lâm Khoa học và Công nghệ Việt Nam, Việt Nam
}

Ngày nhận bài 21-3-2019, ngày chấp nhận 10-5-2019

\section{TÓM TẮT}

Mọt ngô, Sitophilus zeamais (Motschulsky), một loài sâu hại quan trọng đối với ngô hạt và cũng là, loài gây hại phổ biến đối với lúa, đậu đỗ và một số sản phẩm nông nghiệp khác trong các kho bảo quản. Loài sâu hại này thường gây hại đáng kể và rõ ràng nhất đối với ngô hạt trong các kho bảo quản ở Sơn La.

Bài báo này trình bày phương pháp toán học phân tích đặc điểm sinh sản và nhịp điệu đẻ trứng của mọt ngô $S$. zeamais. Trong điều kiện phòng thí nghiệm, với vật liệu thí nghiệm là gạo, thực nghiệm cho thấy, sau khi vũ hóa, mọt trưởng thành $S$. zeamais có thời gian sống rất dài, tới 150 ngày. Trong thời gian này, sau khi ghép đôi được 10 ngày, mọt cái $S$. zeamais bắt đầu đẻ trứng, quá trình đẻ trứng kéo dài cho đến trước khi chết. Trong thời gian trên, mọt cái đẻ trứng không liên tục, mỗi mọt cái đẻ trung bình 38,67 trứng, trong đó có tới $62,81 \%$ số trứng được đẻ vào nửa thời gian đầu (7-8 tuần), chỉ 37,19\% số lượng trứng được đẻ trong thời gian còn lại. Có tới $55,07 \%$ trứng được đẻ trong khoảng thời gian sau 55-95 ngày.

Đặc điểm sinh sản và nhịp điệu đẻ trứng đã được mô tả bằng những đường cong bậc ba cho những khoảng thời gian nói trên. Những đường cong mô tả khá chính xác tỷ lệ trứng được đẻ đạt các đỉnh cao rõ rệt trong khoảng thời gian $15,35,75,95$ và 105 ngày.

Từ khóa: Sitophilus zeamais, mọt ngô, mọt hại kho, nhịp điệu đẻ trứng.

*Địa chỉ liên hệ email: duongdhtb@gmail.com

\section{MỞ ĐÀ̀}

Sitophilus zeamais (Motschulsky) là một trong các loài sâu hại quan trọng đối với nhiều loại hạt ngũ cốc trong các kho bảo quản (Đinh Ngọc Ngoạn, 1964; Bùi Công Hiển, 1995, Bùi Minh Hồng và nnk., 2004). Đặc biệt, loài mọt S. zemais đã được chứng minh hại ngô hạt từ ngoài đồng ruộng, sau khi thu hoạch, loài này tiếp tục sinh sản và phát triển gây hại cho hạt ngô trong các kho bảo quản. Ở Việt Nam, $S$. zeamais không chỉ là một loài gây hại nguy hiểm cho ngô hạt, loài này còn gây hại cho lúa, gạo, đậu đỗ và các sản phẩm nông nghiệp khác trong các kho bảo quản, sự gây hại của loài này làm giảm đáng kể về số lượng và chất lượng sản phẩm nông nghiệp sau thu hoạch (Nguyễn Quang Hiếu và nnk., 2000; Phòng Kiểm dịch thực vật-Cục Bảo vệ thực vật, 2003; Trần Bất Khuất \& Nguyễn Quý Dương, 2005; Nguyễn Quý Dương và nnk., 2009). Đặc biệt, đối với các loại hạt giống được bảo quản trong kho, khi bị S. zeamais gây hại, khả 
năng nảy mầm của hạt giống giảm đáng kể hoặc mất hoàn toàn.

Mọt trưởng thành $S$. zeamais có thời gian sống rất dài, chúng gần như có mặt liên tục trong kho, loài này tồn tại ngay cả khi không có các loại hạt trong kho. Trong điều kiện thí nghiệm với thức ăn mới được cung cấp hàng ngày, mọt trưởng thành có thể sống tới 140-150 ngày, trong thời gian này mọt trưởng thành liên tục đẻ trứng, kết quả trong kho luôn có các giai đoạn phát triển của mọt từ trứng, sâu non, nhộng và trưởng thành (Nguyễn Kim Hoa và nnk., 2008a, 2008b).

Nghiên cứu đặc điểm sinh sản của mọt ngô Sitophilus zeamais nhằm làm rõ sức đẻ và nhịp điệu đẻ trứng của chúng trong thời gian sống, điều này làm cơ sở khoa học giải thích cho hiện tượng có mặt liên tục các giai đoạn phát triển của chúng, giúp tìm kiếm biện pháp hiệu quả phòng chống chúng.

\section{VÂT LIỆ VÀ PHƯƠNG PHÁP NGHIÊN CứU}

Vật liệu ban đầu là mọt trưởng thành $S$. zeamais xuất hiện sau một ngày từ ngô hạt trước khi đưa vào kho bảo quản. Thức ăn được sử dụng để nuôi mọt ngô là gạo thái lan dạng hạt dài, hạt có màu trắng trong, đã được xử lý ở nhiệt độ $60^{\circ} \mathrm{C}$ trong thời gian 120 phút, để trong phòng cho đến khi thủy phần của hạt gạo đạt ở mức 13\%, sau đó chuyển sang giữ trong bình kín để duy trì được thủy phần này trong suốt thời gian thí nghiệm.

Dụng cụ theo dõi trong phòng thí nghiệm gồm tủ sấy hạt, máy đo thủy phần hạt DickeyJohn, sai số $\pm 0,5 \%$; nhiệt ẩm kế Hair Hygrometer, sai số $\pm 1 \%$; kính lúp soi nổi Olympus SZ61có gắn máy ảnh Olympus CX500. Địa điểm tiến hành thí nghiệm: Trường Đại học Tây Bắc, Sơn La.

Sau khi đã chuẩn bị đủ các dụng cụ và vật liệu thí nghiệm, tiến hành nuôi từng cặp mọt (đực + cái) trong lọ nhựa, có kích thước chiều cao $\times$ đường kính miệng $=150 \times 18 \mathrm{~mm}$. Các lo nhựa đều được bịt miệng bằng vải thưa có lỗ nhỏ để ngăn mọt thoát ra ngoài nhưng vẫn đảm bảo được đủ không khí giống với điều kiện bên ngoài.
Gạo được chọn làm thức ăn cho mọt ngô cũng là giá thể đẻ trứng, vì đây là một trong các loại thức ăn thích hợp cho loài $S$. zeamais. Ngoài ra, bề mặt hạt gạo nhẵn, có thể dễ dàng quan sát được trứng mọt ngay sau khi đẻ.

Thả từng cặp mọt vào trong lọ nhựa đã có sẵn 5 hạt gạo với thủy phần đồng đều $13 \%$, có màu sắc trong đồng nhất, không có dấu hiệu bị nấm mốc. Tổng số có 15 cặp mọt được theo dõi trong thí nghiệm. Cứ sau thời gian 24 giờ, đếm số lượng trứng mỗi mọt cái đẻ được, sau đó lấy hết số gạo trong lọ ra rồi thay gạo mới bằng số lượng ban đầu. Thả lại từng cặp mọt đã đưa vào trước đó vào lọ đã có gạo mới.

Sử dụng kính lúp soi nổi để đếm số trứng của mỗi cặp mọt đẻ được từng ngày trên số gạo trong mỗi lọ. Việc thay gạo mới cho đến khi cả mọt đực và mọt cái chết. Tính tổng số trứng của mối mọt cái đẻ được trong toàn bộ thời gian sống và tỷ lệ (\%) trứng của mỗi mọt cái đẻ được sau khoảng thời gian 10 ngày so với tổng số trứng đẻ được trong cả quá trình đẻ trứng. Sử dụng phần mềm Excel để mô tả quá trình đẻ trứng cũng như mô phỏng nhịp điệu đẻ trứng của mọt ngô dưới dạng đường cong bậc 3:

$$
Y=\mathrm{a} t^{3}+\mathrm{b} t^{2}+\mathrm{c} t+\mathrm{d}
$$

Ở đây: $Y=$ tỷ lệ trứng trung bình (\%) mà một mọt cái đẻ được sau thời gian 10 ngày; $t=$ thời gian theo dõi. Trong thí nghiệm với mọt ngô $S$. zeamais, để thuận tiện trong việc mô phỏng nhịp điệu đẻ trứng, thời gian được chia theo lớp với $t=10,15,25, \ldots, 135,145$, giá trị của các hệ số được lấy sau dấu thập phân 5-8 chữ số.

\section{KẾT QUẢ}

Thí nghiệm theo dõi thời gian sống và sức đẻ trứng của mọt ngô $S$. zeamais với thức ăn là gạo thái lan dạng hạt dài cho thấy, sau khi vũ hóa, trong điều kiện được thay thức ăn thường xuyên, thời gian sống của mọt trưởng thành kéo dài từ 80 đến 150 ngày, trung bình 123,5 ngày. Sau khi vũ hóa, mọt trưởng thành thường ghép đôi ngay, tuy nhiên, chỉ sau 10 ngày từ thời điểm khi ghép cặp và giao phối, mọt cái mới bắt đầu đẻ trứng, quá trình đẻ trứng kéo dài cho tới ngày cuối cùng trước khi 
chết. Trong quá trình theo dõi thí nghiệm, mọt đực thường chết trước mọt cái, thời gian sông của mọt đực dao động từ 80 đến 145 ngày, trung bình 119,44 ngày, trong khi đó, mọt cái thường có thời gian sống từ 80 đến 150 ngày, trung bình 125,89 ngày.

Kết quả theo dõi thời gian đẻ trứng của mọt cái $S$. zeamais cho thấy, trong tổng số 15 cặp theo dõi thí nghiệm, 6 cặp có con cái chết trong sau thời gian 10-15 ngày, chỉ còn lại 9 cặp được theo dõi tiếp tục đẻ trứng cho đến 140-145 ngày. Toàn bộ số trứng của 9 cặp này đều được đẻ khá rải rác, vì vậy, để mô tả nhịp điệu đẻ trứng của mọt ngô, chúng tôi sử dụng số trứng cộng dồn trung bình của một mọt cái đẻ được sau mỗi khoảng thời gian 10 ngày và biễu diễn dưới tỷ lệ phần trăm $(\%)$.
Đồ thị mô tả biến động tỷ lệ số trứng mọt cái đẻ được sau mỗi quãng thời gian 10 ngày so với tồng số trứng đẻ được trong suốt thời gian đẻ trứng của mọt cái (bảng 1, hình 1).

Hình 1 cho thấy, thời gian đẻ trứng của mọt cái được mô tả tới 145 ngày, nhịp điệu đẻ trứng đạt những đỉnh cao sau khoảng thời gian theo chu kỳ tương đối rõ rệt. Tỷ lệ trứng của một mọt cái đẻ được đạt các đỉnh cao lần lượt sau những khoảng thời gian 35,65 và 75 ngày, sau đó hầu như giảm rất nhanh sau 80 ngày, trong đó tỷ lệ trứng được đẻ chiếm tới $55,07 \%$ trong khoảng thời gian sau 55-95 ngày, trong khoảng thời gian còn lại, từ 95 đển 145 ngày, chỉ còn $37,19 \%$ số lượng trứng được đẻ (cột 2 , bảng 1 ; hình 1 ).

Bảng 1. So sánh tỷ lệ (\%) trứng trung bình của $S$. zeamais theo thực nghiệm và mô phỏng theo các đường cong lý thuyết

\begin{tabular}{|c|c|c|c|c|c|c|}
\hline \multirow{2}{*}{$\begin{array}{l}\text { Thời gian đẻ } \\
\text { trứng (ngày) }\end{array}$} & \multicolumn{6}{|c|}{ Tỷ lệ trung bình (\%) trứng được đẻ } \\
\hline & $\begin{array}{c}\text { Thực } \\
\text { nghiệm }\end{array}$ & $\begin{array}{c}\text { Lý thuyết } \\
\left(\mathbf{Y}_{\mathrm{a}}\right)\end{array}$ & $\begin{array}{c}\text { Lý thuyết } \\
\left(\mathbf{Y}_{\mathbf{b}}\right)\end{array}$ & $\begin{array}{c}\text { Lý thuyết } \\
\left(\mathbf{Y}_{1}\right)\end{array}$ & $\begin{array}{c}\text { Lý thuyết } \\
\left(\mathbf{Y}_{2}\right)\end{array}$ & $\begin{array}{c}\text { Lý thuyết } \\
\left(\mathbf{Y}_{3}\right)\end{array}$ \\
\hline$(1)$ & (2) & (3) & (4) & $(5)$ & $(6)$ & (7) \\
\hline 10 & 0,6 & & & 0,60 & & \\
\hline 15 & 5,95 & & & 5,96 & & \\
\hline 25 & 2,68 & & & 2,72 & & \\
\hline 35 & 10,12 & & & 10,23 & & \\
\hline Cộng & 19,37 & & & 19,51 & & \\
\hline 45 & 6,55 & & & & 6,47 & \\
\hline 55 & 5,36 & 6,41 & 4,96 & & 6,97 & \\
\hline 65 & 15,18 & 13,30 & 15,23 & & 14,04 & \\
\hline 75 & 16,37 & 15,59 & 14,90 & & 18,61 & \\
\hline 85 & 10,42 & 13,29 & 9,91 & & 11,63 & \\
\hline 95 & 7,74 & 6,40 & 6,19 & & 57,72 & \\
\hline Cộng & 55,07 & 54,99 & 51,19 & & & \\
\hline 105 & 7,44 & & & & & 7,64 \\
\hline 115 & 4,46 & & & & & 3,68 \\
\hline 125 & 2,08 & & & & & 3,26 \\
\hline 135 & 4,16 & & & & & 3,39 \\
\hline 145 & 0,89 & & & & & 1,10 \\
\hline Cộng & 19,37 & & & & & 19,07 \\
\hline
\end{tabular}

Để mô phỏng nhịp điệu đẻ trứng của mọt ngô $S$. zeamais qua tỷ lệ (\%) trứng đạt cao nhất được đẻ trong khoảng thời gian từ sau 55 đến 95 ngày, chúng tôi sử dụng hai dạng 
đường cong phi tuyến, đó là đường cong bậc 2: $Y_{a}=-0,02296 t^{2}+3,44357 t-113,5280\left(\mathrm{R}^{2}\right.$ $=0,83)(t=55,65,75,85,95)$ và đường cong bậc 3: $Y_{b}=0,00099 t^{3}-0,246082 t^{2}+19,84078 t$ - 506,60037 $\left(\mathrm{R}^{2}=0,99\right)(t=55,65,75,85$, $95)$. So sánh các giá trị thực nghiệm và giá trị tính được theo hai đường cong mô phỏng, sự khác nhau ở đây có thể chấp nhận được. Cụ thể, trong khoảng thời gian này, tỷ lệ trứng được đẻ thực tế: 55,07\% (cột 2 bảng 1), trong khi đó số liệu mô phỏng lý thuyết theo đường cong bậc 2 (Ya): 54,99\% (cột 3 bảng 1; hình 2 ); và theo đường cong bậc $3(\mathrm{Yb})$ : $51,19 \%$ (cột 4 , bảng 1; hình 2).

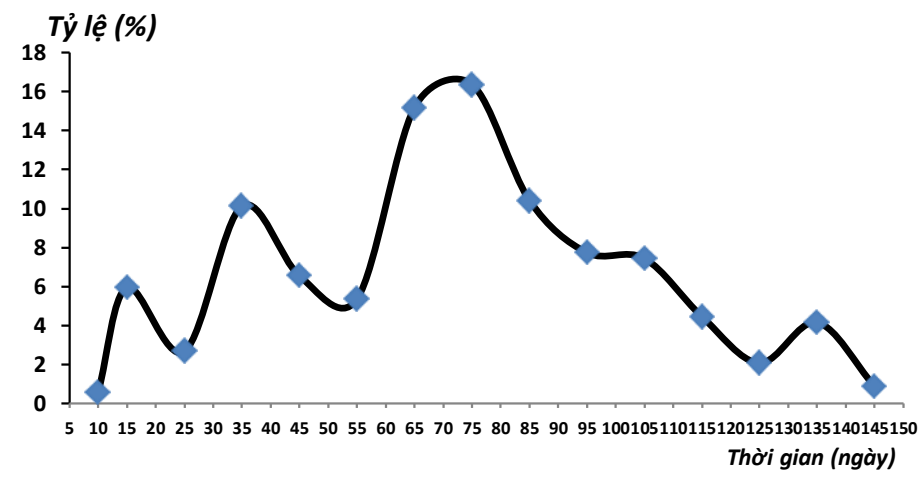

Hình 1. Nhịp điệu đẻ trứng của mọt ngô $S$. Zeamais

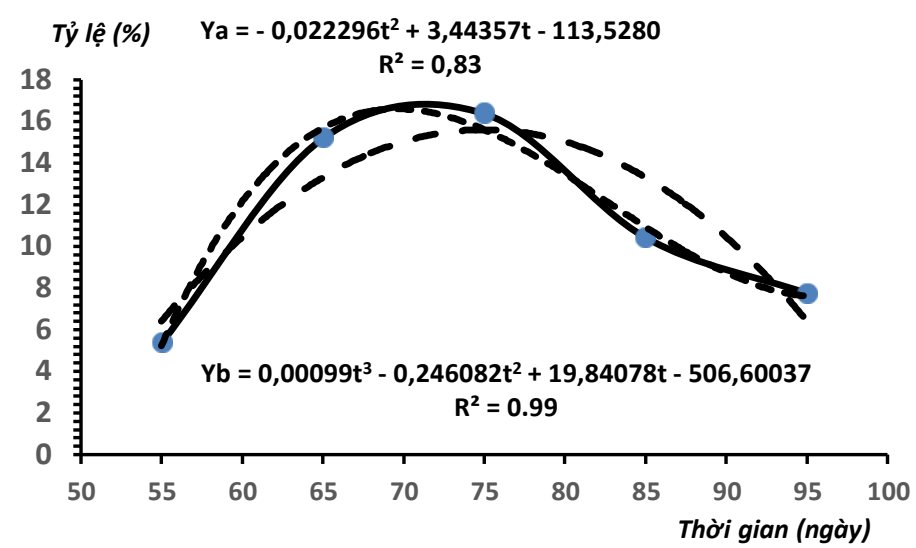

Hình 2. Mô phỏng giai đoạn có tỷ lệ trứng được đẻ cao nhất của mọt ngô $S$. zeamais trong khoảng thời gian từ 55 đến 95 ngày

Chú thích: Đường liền nét là số liệu thực nghiệm, đường đứt quãng là số liệu lý thuyết

Còn giai đoạn đầu của quá trình đẻ trứng ở trưởng thành cái (từ 10-35 ngày), sau các quãng thời gian $t=10,15,25$ và 35 , tỷ lệ trung bình trứng được đẻ bởi một mọt cái $S$. zeamais được mô tả bằng đường cong bậc 3 sau:

$$
Y_{1}=0,00587 t^{3}-0,38650 t^{2}+7,94552 t-46,07250\left(\mathrm{R}^{2}=1,0\right)(t=10,15,25,35) \text { (hình 3) }
$$

Dựa vào tỷ lệ trứng $(\%)$ trung bình mà một mọt cái $S$. zeamais đẻ được sau quãng thời gian 10 ngày so với toàn bộ trứng được đẻ trong suốt thời gian đẻ trứng, đường cong bậc $3\left(Y_{1}\right)$ mô phỏng nhịp điệu đẻ trứng của chúng theo từng quãng thời gian với đô chính xác khá cao $\left(\mathrm{R}^{2}=1,0\right)$ so với số trứng được đẻ thực tế, mô phỏng theo lý thuyết: 19,51\% (bảng 1, cột 5) so với thực nghiệm: 19,37\% (bảng 1 cột 2). 


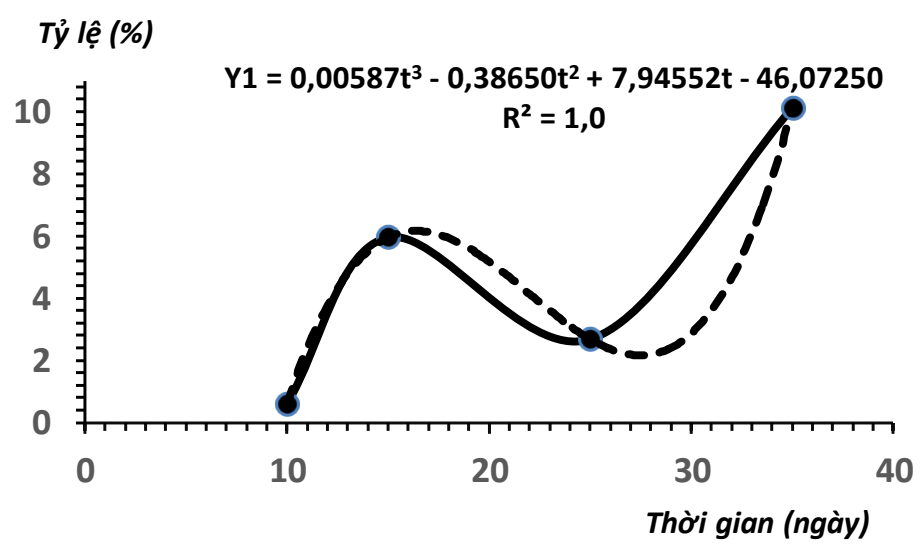

Hình 3. Mô phỏng nhịp điệu đẻ trứng của mọt ngô S. zeamais trong khoảng thời gian từ 10-35 ngày

Chú thích: Đường liền nét là số liệu thực nghiệm, đường đứt quãng là số liệu lý thuyết

Tương tự, giai đoạn từ 45 đến 85 ngày, với lệ trứng được đẻ của một mọt cái $S$. zeamais các quãng thời gian $t=45,55,65,75$ và 85 , tỷ được mô tả bằng đường cong bậc 3 sau:

$$
Y_{2}=-0,00151 t^{3}+0,28197 t^{2}-16,78383 t+328,35131\left(\mathrm{R}^{2}=0,93\right)(t=45,55,65,75,85)(\text { hình 4) }
$$

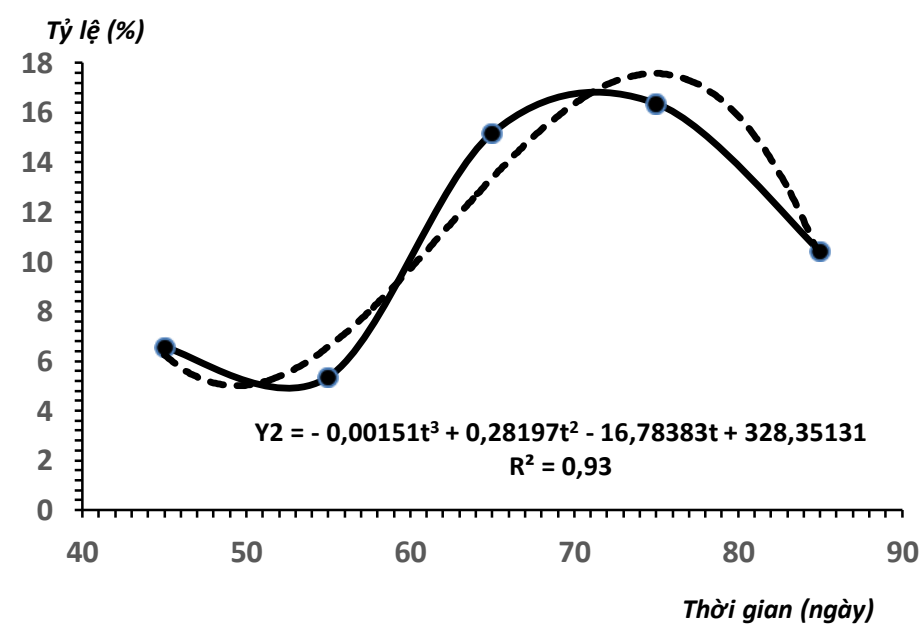

Hình 4. Mô phỏng nhịp điệu đẻ trứng của mọt ngô $S$. zeamais trong khoảng thời gian từ $45-85$ ngày

Chú thích: Đường liền nét là số liệu thực nghiệm, đường đứt quãng là số liệu lý thuyết

Mối tương quan rất chặt chẽ $\left(\mathrm{R}^{2}=0,93\right)$ đã cho thấy, đường cong $\mathrm{Y}_{2}$ có những giá trị rất gần với số liệu thực nghiệm, sai khác không đáng kể giữa tỷ lệ trứng được đẻ theo lý thuyết: $57,72 \%$ (bảng 1 , cột 6 ) và thực nghiệm: $53,88 \%$ (bảng 1 , cột 2 ) vào các ngày $45,55,65,75$ và 85 (cột 6 , bảng 1 ; hình 4).
Giai đoạn cuối cùng của quá trình đẻ trứng ở mọt trưởng thành cái, sau các quãng thời gian $t=105,115,125,135$ và 145 , tỷ lệ trứng trung bình của một mọt cái $S$. zeamais được mô tả bằng đường cong bậc 3 sau:

$$
\begin{gathered}
Y_{3}=-0,00049583 t^{3}+0,18870893 t^{2}- \\
23,90046131 t+1010,65684821\left(\mathrm{R}^{2}=0,89\right) \\
(t=105,115,125,135,145)(\text { hình 5) }
\end{gathered}
$$




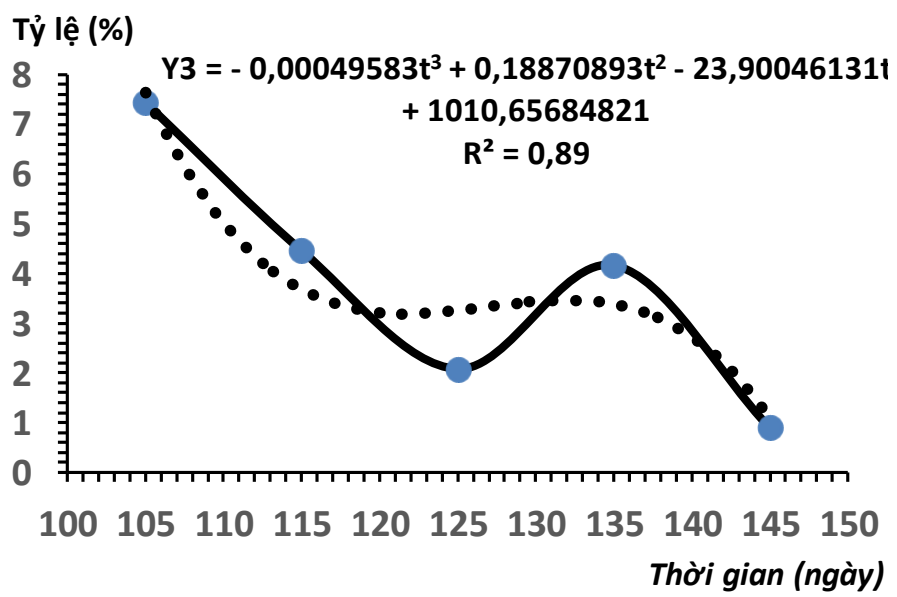

Hình 5. Mô phỏng nhịp điệu đẻ trứng của mọt ngô $S$. zeamais trong khoảng thời gian từ 105-145 ngày

Chú thích: Đường liền nét là số liệu thực nghiệm, đường đứt quãng là số liệu lý thuyết

Từ đường cong hình 5 mô tả quá trình đẻ trứng có thể so sánh tỷ lệ trứng trung bình của một mọt cái đẻ theo lý thuyết: 19,07\% (bảng 1 , cột 7) và tỷ lệ trứng được đẻ thực tê: 19,37\% (bảng 1, cột 2) có sự sai khác không đáng kể so với các giai đoạn trước đó. Như vậy dựa vào hệ số tương quan $\mathrm{R}^{2}=0,89$ và tỷ lệ trứng được đẻ bởi mỗi mọt cái tính theo lý thuyết có sai khác khá nhỏ so với số liệu thực nghiệm hoàn toàn có thể chấp nhận đường cong bậc 3 để mô phỏng nhiệp điệu đẻ trứng của mọt ngô $S$. zeamais.

\section{THẢO LUẬN}

Trưởng thành mọt ngô $S$. zeamais, thuộc nhóm côn trùng có thời gian sống dài, điều này dẫn đến việc đẻ trứng rải rác và kéo dài trong suốt thời gian sống của trưởng thành. Đặc điểm đẻ trứng này của $S$. zeamais hầu như chưa thấy đề cập đến trong những công bố trước đây (Nguyễn Kim Hoa và nnk., 2008a, 2008b). Trong điều kiện thí nghiệm nuôi nhốt ở không gian hẹp, thời gian sống và đẻ trứng của mọt ngô có thể ngắn hơn so với điều kiện tự nhiên trong các kho bảo quản (CABI, 2010). Tuy nhiên, số lượng trứng của mọt cái đẻ được luôn có xu hướng đạt cao nhất vào giữa thời gian sống khi mọt cái có tuổi sinh lý tốt nhất.

Hiện tượng mọt ngô $S$. zeamais có thời gian đẻ trứng kéo dài cũng đã được đề cập
(CABI, 2010; Nguyễn Kim Hoa và nnk., 2008a), tuy nhiên, chưa tài liệu nào mô phỏng nhịp điệu đẻ trứng trong thời gian dài của loài này. Khi sử dụng đường đường cong bậc 3 để mô phỏng nhịp điệu đẻ trứng theo từng giai đoạn, trong các phương trình bậc 3 , khi giá trị các hệ số được lấy từ 5 đến 8 chữ số thập phân, số liệu mô phỏng theo lý thuyết càng gần với số liệu thực nghiệm.

Ở hầu hết các loài côn trùng có tập tính đẻ trứng rời rạc, không đẻ theo ồ, lượng trứng thường được đẻ đạt cao nhất vào khoảng giữa thời gian của quá trình đẻ trứng, điều này đã được chứng minh ở các nhóm côn trùng khác với trưởng thành có thời gian sống ngắn hơn và quá trình đẻ trứng không quá dài như ở sâu đo xanh hại đay, Anomis flava (Khuất Đăng Long, 1986), ở ruồi đục thân đậu tương (Khuat Dang Long, Dy Sam An, 2001; Dy Sam An, Khuat Dang Long, 2003), ở loài ong ngoại ký sinh Anisopteromalus calandrae (Nguyễn Thị Oanh và nnk., 2017).

Trưởng thành mọt ngô có thời gian sống dài, sức đẻ trứng không cao nhưng chúng có tập tính đẻ rải rác suốt trong thời gian sống của trưởng thành, vì vậy, trong các kho bảo quản ngô ở Sơn La, có thể bắt gặp tất cả các giai đoạn phát triển từ trứng, sâu non, nhộng đến trưởng thành $S$. zeamais. Đến nay, chưa có biện pháp hiệu quả nào để phòng chống loài mọt ngô $S$. zeamais. Hơn nữa, ở Sơn La, 
sau khi thu hoạch, ngô hạt được chuyển ngay vào kho bảo quản hoặc ngô hạt được chuyển từ các kho bảo quản khác đến thường đã có sẵn bên trong đầy đủ các pha phát triển, mọt ngô tiếp tục phát triển, sinh sôi trong quá trình vận chuyển cũng như sau khi đến kho mới.

Để phòng trừ mọt ngô có hiệu quả nên tập trung vào việc giám sát nguồn ngô hạt bị nhiễm mọt $S$. zeamais trước khi đưa vào kho bảo quản; vệ sinh kho bảo quản nhằm loại trừ những nguồn hạt cũ và vật chứa mọt còn lại trong kho trước khi đưa hạt mới vào trong kho.

\section{KẾT LUẬN}

Trong các kho bảo quản nông sản, đặc biệt đối với ngô hạt trong các kho bảo quản ở Sơn La, S. zeamais được xác định là một trong các loài sâu hại phổ biến. Mọt ngô $S$. zeamais thường xuyên có mặt trong các kho bảo quản do trưởng thành có thời gian sống và đẻ trứng kéo dài, tới 150 ngày. Thực nghiệm theo dõi sức đẻ trứng của mọt ngô $S$. zeamais với thức ăn là gạo, mỗi mọt cái đẻ trung bình 38,67 trứng, trong đó có tới $62,81 \%$ số trứng được đẻ vào nửa thời gian đầu, chỉ còn $37,19 \%$ số lượng trứng được đẻ trong thời gian còn lại.

Việc sử dụng đường cong bậc 3 cho phép mô phỏng khá chính xác nhịp điệu đẻ trứng của mọt ngô sau các quãng thời gian 10 ngày từ khi bắt đầu đẻ trứng cho đến khi kết thúc quá trình đẻ trứng. Trong thực tế, việc gặp khó khăn trong phòng chống loài này do thời gian đẻ trứng $S$. zeamais kéo dài và luôn tồn tại tất cả các pha phát triển của chúng trong kho bảo quản ngô hạt ở Sơn La.

\section{TÀI LIÊU THAM KHẢO}

Bùi Công Hiển, 1995. Côn trùng hại kho, Nxb Khoa học và Kỹ thuật, Hà Nội. 216 tr.

Bùi Minh Hồng, Hà Quang Hùng, 2004. Thành phần loài sâu mọt và thiên địch trên thóc bảo quản đổ rời tại kho cuốn của Cục Dự trữ quốc gia vùng Hà Nội và phụ cận. Tạp chí Bảo vệ thực vật, số 2: 3-6.

CABI, 2010. Sitophilus zeamais (maize weevil) datasheet. Crop Protection Compendium, 2010 Edition. CAB International Publishing. Wallingford,
UK. www.cabi.org/cpc. Accessed on 28 Jan 2019.

Dy Sam An, Khuat Dang Long, 2003. Mating behaviour and egg laying rhythm of the soybean fly, Ophiomyia phaseoli Tryon (Diptera: Agromyzidae), Proceedings, Vietnamese Norwegian Workshop, Hanoi 17-18 October 2002. Gronn Kunnskap, 7(17): 37-42

Đinh Ngọc Ngoạn, 1964. Kết quả điều tra côn trùng hại kho ở miền Bắc Việt Nam. Tạp chí Khoa học kỹ thuật Nông nghiệp, số 4: 115-121.

Khuất Đăng Long, 1986. Tập tính ghép đôi và nhịp điệu đẻ trứng của sâu đo xanh hại đay Anomis flava F. Tap chi Sinh hoc, 8(2): $15-17$.

Khuất Đăng Long, Dy Sam An, 2001. Tập tính ghép đôi và nhịp điệu đẻ trứng của ruồi đục thân đậu tương Melanogromyza sojae (Diptera: Agromyzidae), Tap chi Sinh hoc, 23(4): 18-23.

Nguyễn Kim Hoa, Nguyễn Văn Liêm, Trần Thị Hường, Nguyễn Thị Hiền, 2008a. Đặc điểm sinh học chủ yếu của mọt ngô Sitopphilus zeamais Motch. (Col: Curculionidae). Hội nghị c.ôn trùng toàn quốc lần thứ $6, \mathrm{Nxb}$ Nông nghiệp, $\mathrm{H}$.: 560-569.

Nguyễn Kim Hoa, Nguyễn Văn Liêm, Trần Thị Hường, Nguyễn Thị Hiền, 2008b. Thành phần và mức độ gây hại của các loài mọt trong ngô bảo quản tại hộ gia đình ở vùng Bắc Hà, Lào Cai. Hội nghị côn trùng toàn quốc lần thứ $6, \mathrm{Nxb}$ Nông nghiệp, H.: 634-638.

Nguyễn Quang Hiếu, Lương Thị Hải, Bùi Công Hiển, 2000. Một số kết quả điều tra côn trùng hại kho thóc dự trữ ở Hà Nội và Hải Phòng. Tạp chi Bảo vệ thực vật, số 5: 11-14.

Nguyễn Quý Dương, Vũ Thị Hải, Nguyễn Viết Hải, Lê nhật Thành, Hồ Thị Xuân, Hương, Vũ Quang Côn, 2009. Thành phần loài côn trùng gây hại trên hại đậu đỗ sau thu hoạch ở miền Bắc Việt Nam 2006-2008. Tạp chí Bảo vệ thực vật, số 2: 11-17. 
Nguyen Thi Oanh, Tran Ngoc Lan, Truong Xuan Lam, 2017. Egg-lying behavior of Anisopteromalus calandrae (Howard), an ectoparasitoid of Lasioderma serricorne (Fabricius). Tap chi Sinh hoc, 39(4): 416-420. https://doi.org/10. 15625/0866-7160/v39n4.10935

Phòng Kiểm dịch thực vật-Cục Bảo vệ thực vật, 2003. Thành phần côn trùng hại kho ở
Việt Nam năm 1996-2000, Một số ứng dụng bảo vệ thực vật vào sản xuất nông nghiệp 1998-2002, Nxb Nông nghiệp, H.: 260-269.

Trần Bất Khuất, Nguyễn Quý Dương, 2005. Thành phần sâu mọt hại lạc nhân trong kho bảo quản tại một số vùng năm 2004. Tạp chi Bảo vệ thự vật, số 1: 11-15. 